\title{
Effects of Sled Velocity on Fabric Friction
}

\author{
J. O. Ajayi*, H. M. Elder**, K. A. Bello*** \\ E. G. Kolawole***, M. I. Darma***
}

\begin{abstract}
The influence of velocity of sliding on some new frictional parameters of weft pile fabrics is reported. The frictional amplitude diminish as the velocity of motion increased. The kinetic frictional resistance also diminish initially, and then increased as the velocity of sliding increased. The initial decrease in resistance to motion is attributed to viscoelastic effects while the increase in resistance to motion at higher speeds is ascribed to mechanical interlocking of surface structure. The amplitude of frictional resistance and number of peaks are shown to be related to some partinent fabric properties such as cord height and number respectively.
\end{abstract}

(Received June 17, 1996)

(Accepted for Publication July 4, 1998)

\section{Introduction}

In some systematic studies of frictional properties of fabrics ${ }^{1-4)}$ the effects of fibre content ${ }^{1)}$, yarn mechanical properties ${ }^{2)}$, fabric structure $^{3)}$, and finishing treatments ${ }^{4)}$ were considered. The influence of experimental variables, such as normal load, area of contact and the nature of sled surfaces were investigated ${ }^{5}$. We have not as yet considered in detail the influence of velo city of sliding on some new frictional parameters such as frictional resistance, amplitude and number of peaks of the stick-slip motion. Since these parameters are related to fabric handle ${ }^{1-4)}$ and quality ${ }^{1)}$ their consideration was thought useful.

In some earlier investigations, Nishimatsu and Sawaki ${ }^{6,7)}$ studied the frictional properties and handle of some warp pile (terry towel) cotton fabrics. These authors considered the effects of normal load ${ }^{7}$, area of contact $^{(6)}$ relative humidity and velocity of sliding ${ }^{7}$. They found that the frictional resistance increased as the normal load and area of contact increased. The frictional resistance diminished at first $(0.5-5.0 \mathrm{~m} / \mathrm{s})$, and then increased again as the velocity of sliding increased $^{7}$. Although these authors did not explain their observations, it is reasonable to assume that an increase in velocity implies a reduction in the time of contact between the rubbing surfaces. For viscoelastic materials such as fabrics, the deformation is expected to increase as the time of contact increases ${ }^{8)}$ therefore, an increase in sled velocity should result in a decrease in frictional resistance. This hypo thesis is tested in this work.

Nishimatsu and Sawaki ${ }^{\text {l) }}$ also showed the fric tional traces of fabrics at different speeds. Clear$1 y$, their results show that the stick-slip pulses (amplitude) gradually diminished as the speed increased. Since the effects of velocity on some of the stick-slip parameters, such as number of

*Abubakar Tafawa Balewa University, Industrial Chemistry Programme, P. M. B. 0248, Bauchi.

**University of Strathclyde, Department of Pure \& Applied Chemistry, Fibre and Textile Research Unit, 295 Cathedral Street, Glasgow, G1 1XL, U. K.

${ }^{* * *}$ Ahmadu Bello University, Department of Textile Science \& Technology, Zaria, Nigeria. 
peaks, amplitude and frictional resistance, are not frequently a subject of experimental scrutiny, they are considered in this investigation. However, before the discussion of experimental results, it is partinent to examine the theoretical basis of the stick-slip phenomenon, and the manner in which it is affected by the velocity of sliding.

\section{Theoretical Background}

Theoretically, the frictional resistance between two bodies depends upon the intimacy of contacts $^{1)}$, yield pressure ${ }^{5)}$, shear strength of the junction $^{8)}$ and the velocity of sliding ${ }^{1,8,12}$. Any experimental variation that alters any one or more of these factors would also lead to an alte ration of frictional properties. Considering a general case in which a sled of mass $m$, sliding over a fabric with a uniform velocity $v$, and suppose the sled is driven by a constant rate of elongation tester which acts as an elastic system ${ }^{12}$. The spring deflexion of the load cell of the tester is a measure of the frictional resistance $F$. Assuming the spring constant of the load cell is $\mathrm{c}$, the spring displacement $x$ of the load cell is expressible by the following equation

$$
F=-c x
$$

(the negative sign is indicative of a frictional resistance acting in opposition to an increasing $x$ ). Assuming there is no damping, the equation of motion in free oscillation is given by :

$$
m \frac{d^{2} x}{d y^{2}}=-c x
$$

This is a simple harmonic equation of frequency $f$, where

$$
f=\frac{1}{2 \pi} \sqrt{\frac{c}{m}}
$$

Assuming the asperities on the sled and fabric surfaces intermesh, as is likely to be the case in weft pile corduroy fabrics ${ }^{3)}$, so that the two surfaces travel together without relative motion until the force on the fabric is equal to the static friction, $F s$;

$$
F s=\mu N
$$

$$
\begin{aligned}
& \quad \mu=\frac{1}{N_{2}-N_{1}} \int_{N_{1}}^{N_{2}}(F / N) \cdot d F \\
& \quad F=K N^{n} \\
& \mu=\text { coefficient of friction } \\
& N=\text { normal load } \\
& K=\text { frictional constant } \\
& n=\text { frictional index. }
\end{aligned}
$$

$N=$ normal load

Reference to the hypothetical stick-slip trace in Figure 1 will show that the deflexion by surface asperities is linear with time and deflexion $B X$ is given by :

$$
B X=\frac{F s}{c}
$$

At point $B$, slip will occur, therefore

$$
\frac{d^{2} x}{d t^{2}}-F K=-c x
$$

At the initial instant when $t=0$ (i. e. point $B$ in Figure 1), the displacement $x$ and the forward velocity $d x / d t$ equals to $v$.

The solution to equation 8 is given by :

$$
x=\frac{m}{c}\left[(F s-F k)(\cos \omega t+F k]+\frac{\nu}{\omega} \sin \omega t\right.
$$

where $\omega^{2}=c / m$

If the relative displacement of the asperities on fabric surface is small compared to the mean velocity of the sled, the last term of equation 9 may be neglected, thus :

$$
x=\frac{m}{c}[(F s-F k) \operatorname{Cos} \omega t+F k]
$$

Thus the motion of the sled has the same natural frequency as before it comes to rest relative to that of the fabric, that is, it sticks again when $d x$ / $d t=v$. If $v$ can be neglected it may be considered that sticking recurs when $d x / d t=0$, i. e. when $\omega t$ $=\pi$. This will correspond to the natural period of the system. Substituting the value of $\omega t$ into equation 10 yields :

$$
x=\frac{m}{c}(2 F k-F s)
$$

By definition ${ }^{1,5,8,12)}$, the amplitude or the size of the stick-slip, from peak to trough as depicted in Fig. 1 is given by :

$$
B C=B X-C Y=F s-F o
$$

where 
Table 1 Details of Weft Pile Fabrics

\begin{tabular}{|c|c|c|c|c|c|c|c|c|c|c|}
\hline \multirow{2}{*}{$\begin{array}{r}\text { Fabric } \\
\text { Code }\end{array}$} & \multicolumn{2}{|c|}{ Fibre Content } & \multirow{2}{*}{\begin{tabular}{|c} 
Fabric \\
Sett \\
$(\mathrm{Tnd} / \mathrm{cm})$ \\
\end{tabular}} & \multirow{2}{*}{$\begin{array}{l}\text { Yarn } \\
\text { Count } \\
\text { (Tex) } \\
\end{array}$} & \multirow{2}{*}{$\begin{array}{l}\text { Yarn } \\
\text { Crimp } \\
(\%)\end{array}$} & \multirow{2}{*}{$\begin{array}{l}\text { Thickness } \\
\text { (mm) }\end{array}$} & \multirow{2}{*}{$\begin{array}{l}\text { Weight } \\
\left(\mathrm{g} / \mathrm{m}^{2}\right)\end{array}$} & \multirow{2}{*}{$\begin{array}{l}\text { NO. of }{ }^{b} \\
\text { cords } \\
\text { (per5cm) }\end{array}$} & \multirow{2}{*}{$\begin{array}{l}\text { Cord }^{b} \\
\text { Width } \\
\text { (mm) }\end{array}$} & \multirow{2}{*}{$\begin{array}{l}\text { Cord }^{c} \\
\text { Height } \\
(\mathrm{mm})\end{array}$} \\
\hline & Base & Pile & & & & & & & & \\
\hline $\begin{array}{l}P_{1}{ }^{P} \\
P_{T}\end{array}$ & Polypropylene & Polyacrylics & $\begin{array}{l}30 \\
16\end{array}$ & $\begin{array}{l}31 \\
16\end{array}$ & $\begin{array}{c}9.8 \\
16.3\end{array}$ & 2.88 & 340 & (8) 8 & 6.0 & 1.56 \\
\hline $\mathrm{P}_{2}{ }^{\mathrm{P}}$ & Cotton & Polypropylene & $\begin{array}{l}24 \\
20\end{array}$ & $\begin{array}{l}40 \\
56\end{array}$ & $\begin{array}{c}18.3 \\
1.2\end{array}$ & 2.24 & 370 & 17 & 3.1 & 1.16 \\
\hline $\mathrm{P}_{3}{ }^{\mathrm{P}}$ & Polyacrylics & Polyacrylics & $\begin{array}{l}36 \\
30\end{array}$ & $\begin{array}{l}28 \\
36\end{array}$ & $\begin{array}{c}3.5 \\
24.5\end{array}$ & 2.68 & 220 & 35 & 1.2 & 1.68 \\
\hline $\mathrm{P}_{4}{ }_{\mathrm{T}}^{\mathrm{P}}$ & Cotton & Polypropylene & $\begin{array}{l}13 \\
12\end{array}$ & $\begin{array}{l}52 \\
59\end{array}$ & $\begin{array}{c}6.3 \\
13.1\end{array}$ & 2.06 & 204 & 12 & 4.0 & 0.48 \\
\hline $\begin{array}{l}\mathrm{P}_{5}{ }^{2} \\
{ }_{T}\end{array}$ & Cotton & Cotton & $\begin{array}{l}28 \\
15\end{array}$ & $\begin{array}{l}34 \\
60\end{array}$ & $\begin{array}{c}7.1 \\
16.0\end{array}$ & 2.30 & 369 & 13 & 3.5 & 1.27 \\
\hline
\end{tabular}

b Test method : Cooke's micrometar (essentially a microscope with a traversing eye piece)

c Measured on the projecttion microscope (Text. Res. J., 62, 57, (1992)

$\mathrm{P}=$ Werp

$\mathrm{T}=$ Weft

Value in parenithesis refer to smaller cord

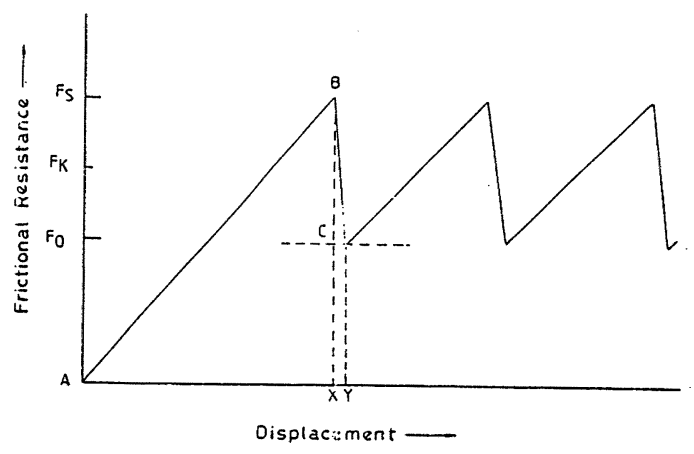

Fig. 1 Hypothetical stick-slip friction traces of fabrics.

Since $x$ is equal to $C Y$ it is clear from equation 11 that the larger the value of $F k$, the smaller the amplitude. In the limit when $F s=F k$, the amplitude becomes zero, so that the sliding remains steady, i. e. without the stick-slip characteristics. As Fk decreases, the amplitude increase in size. In the limit when $F k$ is zero, a swing beyond the zero position is envisioned. This will correspoind to a theoretical maximum amplitude. Since the value of $F k$ could never be zero,

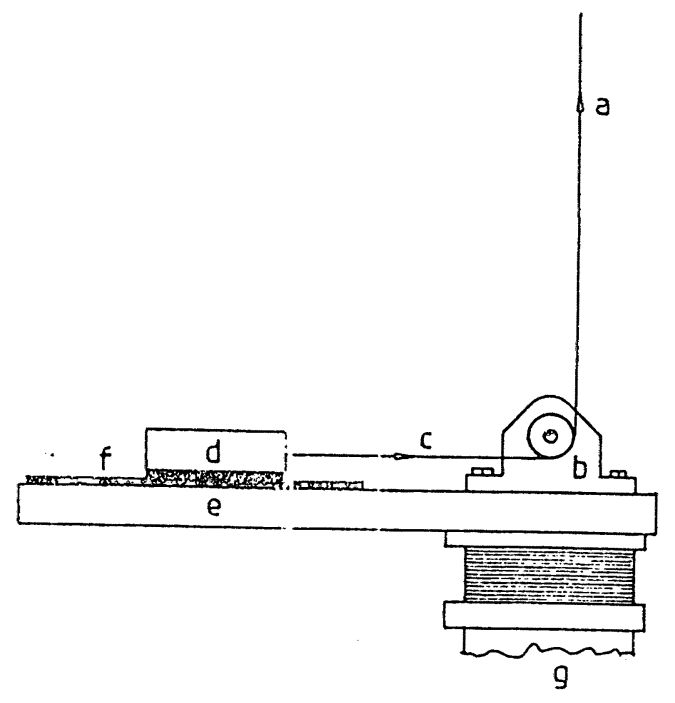

Fig. 2 Sketch of the fabric friction measurement on a flat horizontal platform

$\mathrm{a}=$ instron load cell

$\mathrm{b}=$ frictionless pulley

$\mathrm{c}=$ towing cord

$\mathrm{d}=$ sled covered with fabric

$\mathrm{e}=$ horizontal platform

$\mathrm{f}=$ fabric specimen,

$\mathrm{g}=$ connection to the bottom jaw. 


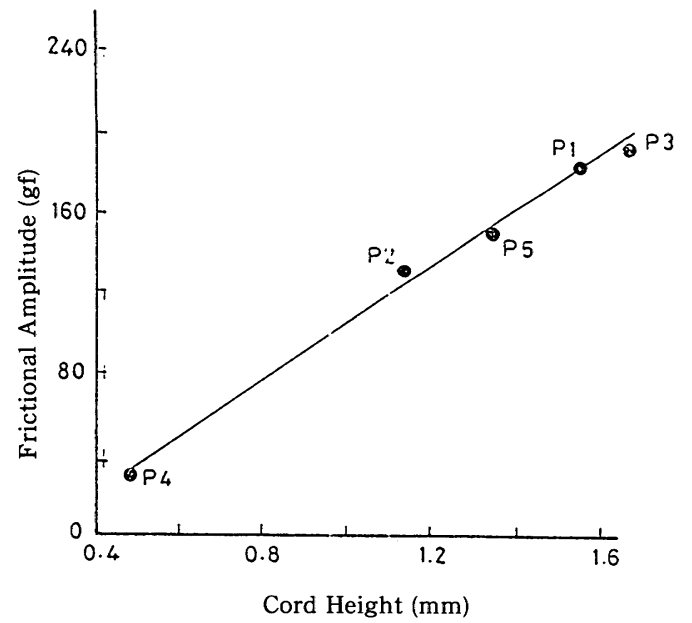

Fig. 3 Relationship between the cord height and amplitude of the stick-slip friction traces.

the stick-slip amplitude could never be as pronounced. This hypothetical consideration suggests that an increase in the velocity of sliding is expected to decrease frictional resistance and amplitude of the stick-slip motion. This hypothesis is tested in this investigation.

\section{Experimental}

The purpose of this investigation is to demonstrate the relationship betwen some new frictional properties of fabrics and velocity. In some previous studies ${ }^{1-7)}$, some links have been established between fabric friction and handle ${ }^{1-5,15}$, such as smoothness ${ }^{3)}$. However, there is no systematic studies of the effects of sliding velocity on some of these new frictional parameters which also affect fabric handle. This paper also bridges this gap.

In some previous studies, Nishimatsu and Sawaki ${ }^{6,7)}$ used pile fabrics in their frictional investigations. Similar fabrics are also used here to facilitate comparision of results. The fabric samples used in this investigation consist of five weft pile woven fabrics, with variation in number, height and width of fibre piles. Fabric mass range from $204 \mathrm{~g} / \mathrm{m}^{2}$ to $370 \mathrm{~g} / \mathrm{m}^{2}$, and thickness from $2.06 \mathrm{~mm}$ to $2.88 \mathrm{~mm}$. Further details may be found in Table 1 .

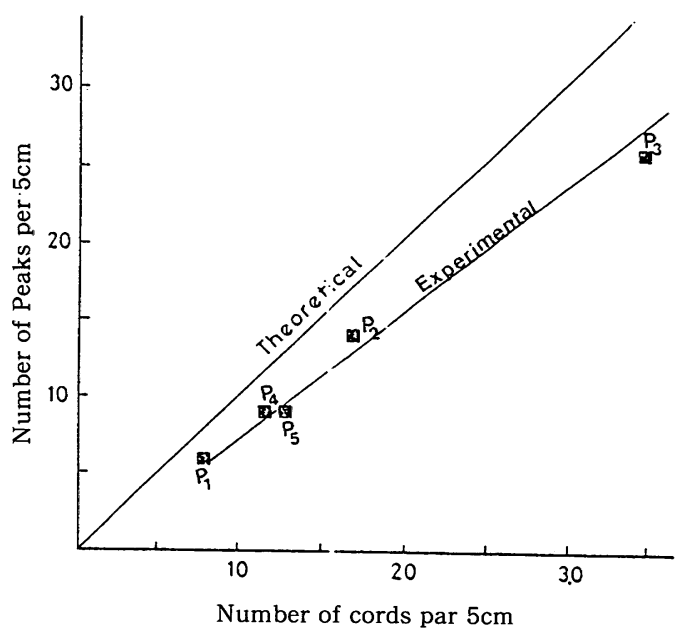

Fig. 4 Relationship between the number of cords and the number of stick-slip pulses.

\subsection{Fabric Friction Measurement}

For the friction measurements, we used an Instron tensile tester (model 1122) fitted with an appropriate friction assembly, i. e. aluminium platform, in accordance with the ASTM procedure ${ }^{13)}$. The principle of the measurements was based on the rectilinear motion of a sled over a horizontal platform $(52 \times 15 \mathrm{~cm})$. A light wooden sled $(8 \times 5 \mathrm{~cm})$ weighing $200 \mathrm{~g}$ (i. e. $400 \mathrm{~N} /$ $\mathrm{m}^{2}$ pressure) was pulled at the required velocity by the Instron crosshead by means of an inextensible towing yarn passing over a frictionless pulley, as shown in Fig. 1. Both chart speed $(5 \mathrm{~cm} / \mathrm{min})$ and full scale deflection $(200-2000 \mathrm{~g})$ were selected to give maximum reproducible frictional parameters.

The frictional properties of a fabric were measured by mounting a rectangular specimen $(30 \times$ $10 \mathrm{~cm}$ ) on a horizontal platform over which a sled covered with an identical fabric was drawn. The fabric on the platform was smoothed by hand and held under a slight tension by bull-dog clips, which ensured that the sample did not wrinkle or buckle during the tests. The fabric specimen on the sled was also slightly tensioned and fastened on the upper surface with doublesided tape. The fabric was tested across the direction of cords at different velocities. Fresh 


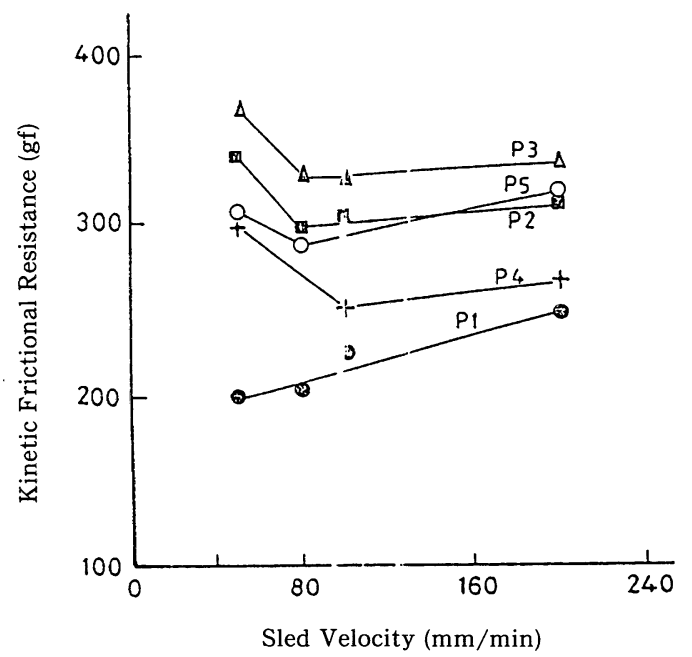

Fig. 5 Effects of sled velocity on the kinetic frictional resistance of fabrics.

samples were used for all tests, and each fabric specimen was tested five times.

\subsection{Expression of Results}

The frictional parameters enumerated here were determined by trace analysis in accordance with a procedure used by several other investigators ${ }^{1-5,7,12)}$. Both static and kinetic frictional resistance were determined from the frictional trace. The highest peak at the beginning of motion was taken as the static frictional resistance ${ }^{1,7,12}$. The mean of peaks and troughs (equivalent to drawing a straight line through the middle of the stick-slip pulses) was taken as the kinetic frictional resistance ${ }^{5)}$

The amplitude of frictional resistance was taken as the height (i. e. peak to trough) of the stick-slip pulses, excluding the first peak, which might be due to static effect $t^{1,2,4)}$. We then counted the number of distinctive peaks in a $5 \mathrm{~cm}$ traverse of the sled ${ }^{1,2,5)}$.

\section{Results and Discussion}

Reference to Table 2 will show the frictional properties of fabrics at different velocities. The static frictional resistance of fabrics $\mathrm{P}_{2}$ and $\mathrm{P}_{5}$ increase, while that of fabric $\mathrm{P}_{4}$ decrease, with an increase in the velocity of sliding. There was no

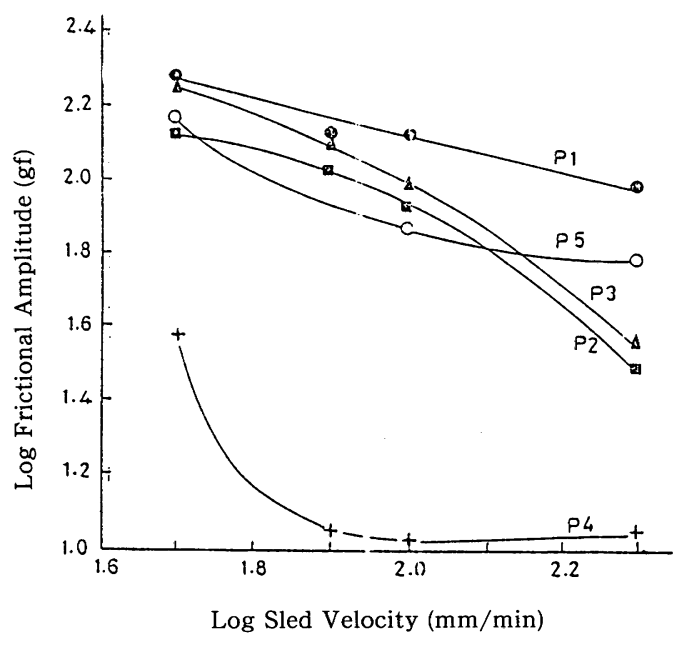

Fig. 6 Effects of sled velocity on the amplitude of the stick-slip traces.

consistent change in the static frictional resistance of fabrics $P_{1}$ and $P_{3}$. Perhaps this inconsistent result is due to the static effect which is partly governed by the intermeshing of fibre piles $^{1,3,5)}$ and partly by the viscoelastic nature of the fabric surface owing to compression ${ }^{8,15)}$.

The number of stick-slip peaks (Table 2) is insignificantly affected by the velocity of sliding. This may be due to the relatively large size of cords on fabric surface, although the low range of velocities employed $(5-20 \mathrm{~cm} / \mathrm{min})$ in this study may also be a factor. The relationship between the cord height and the amplitude of the stick-slip frictional traces is depicted in Fig. 3. This shows an excellent linear correlation (regression coefficient $=0.98$ ). Similar results obtained in some earlier studies ${ }^{1,25)}$ were attributed to an increase in the resistance to motion as the height of fibre pile increased. The relationship between the number of cords on fabric surface and the number of peaks of the stick-slip frictional trace is depicted in Fig. 4. The number of cords detected in all fabrics using the friction trace is lower than the theoretical maximum, i. e. the number of cords on the fabric surface. It is also interesting to note that the divergence of this agreement increases as the number of cords increase. This is not surprising because the 
Table 2 Effects of sled velocity on frictional properties of fabrics (normal pressure $=400 \mathrm{~N} / \mathrm{m}_{2}$, time of loading ; $3 \mathrm{~min}$, surface $=$ fabric - on fabric)

\begin{tabular}{c|c|c|c|c|c|c}
\hline \hline \multirow{2}{*}{$\begin{array}{c}\text { Frictional } \\
\text { parameters }\end{array}$} & \multirow{2}{*}{$\begin{array}{c}\text { Velocity } \\
(\mathrm{mm} / \mathrm{min} .)\end{array}$} & \multicolumn{5}{|c}{ Fabrics } \\
\cline { 3 - 7 } & 50 & $\mathrm{P}_{1}$ & $\mathrm{P}_{2}$ & $\mathrm{P}_{3}$ & $\mathrm{P}_{4}$ & $\mathrm{P}_{5}$ \\
\hline & 80 & 350 & 447 & 407 & 360 \\
Fs & 100 & 280 & 375 & 467 & 430 & 373 \\
(gf) & 200 & 280 & 405 & 420 & 305 & 395 \\
& 50 & 200 & 340 & 370 & 297 & 440 \\
\hline & 80 & 205 & 300 & 328 & 290 & 295 \\
Fk & 100 & 230 & 310 & 327 & 252 & 325 \\
(gf) & 200 & 250 & 325 & 370 & 270 & 335 \\
\hline & 50 & 184 & 133 & 192 & 36 & 146 \\
& 80 & 133 & 104 & 126 & 11 & 143 \\
Fa & 100 & 132 & 83 & 87 & 11 & 72 \\
(gf) & 200 & 95 & 31 & 33 & 12 & 60 \\
\hline & 504 & 10 & 11 & 26 & 9 & 9 \\
Fn & 80 & 10 & 11 & 26 & 8 & 9 \\
(per 5cm) & 100 & 11 & 11 & 30 & 9 & 9 \\
& 200 & 9 & 11 & 28 & 8 & 9 \\
\hline
\end{tabular}

Fs $=$ Static frictional resistance

$\mathrm{Fk}=$ Kinetic frictional resistance

$\mathrm{Fa}=$ Frictional amplitude

$\mathrm{Fn}=$ Number of stick-slip peaks per $5 \mathrm{~cm}$. see fabric details in Table 1

greater the number of cords, the less the chances of mechanical interlocking of surface structure $^{1,5,15)}$ i. e. cords, and ribs, the lower the number of cords detectable on fabric surfaces.

The results in Fig. 5 show that, with the possible exception of fabric $P_{1}$, in which the kinetic frictional resistance consistently increase, all other fabrics show an initial decline in resistance, followed by an increase. This agrees with the results of Nishimatsu and Sawaki ${ }^{7)}$ for fabrics, and several other workers for yarns ${ }^{8-11)}$. However, this contradicts our earlier hypothesis in which it was wholely assumed that the kinetic frictional resistance is deformation controlled, and as such any increase in velocity should bring about a decrease in contact time of the sliding members which will in turn reduce the resistance to motion. It is likely that two separate factors are involved. The initial decrease at low speed, i. e. longer contact time, may be gover ned by the visco-elastic nature of fabric surfaces. At higher speed, i. e. shorter contact time, the mechanical interlocking of surface asperities may be responsible for the increased resistance to motion. The reason for the consistent increase in kinetic frictional resistance of fabric $P_{1}$ as the velocity increased is not clear, but may by due to the predominent effect of mechanical interlocking over the viscoelastic-effect, thus the double cord nature of the surface (Table 1) may provide a good anchorage of the fibre pile and resistance to slippage at lower speed ${ }^{1,14}$. Refere nce to Fig. 6 will show that the amplitude of the stick-slip motion diminish as the velocity increased. As stated earlier in equation 10, the motion of the sled is oscillatory, i. e. sticking will occur when $d x / d t=v$. At low values of v, i. e. $d x /$ $d t=0$ or $\omega t=\pi$ in equation 10 , slipping will occur, 

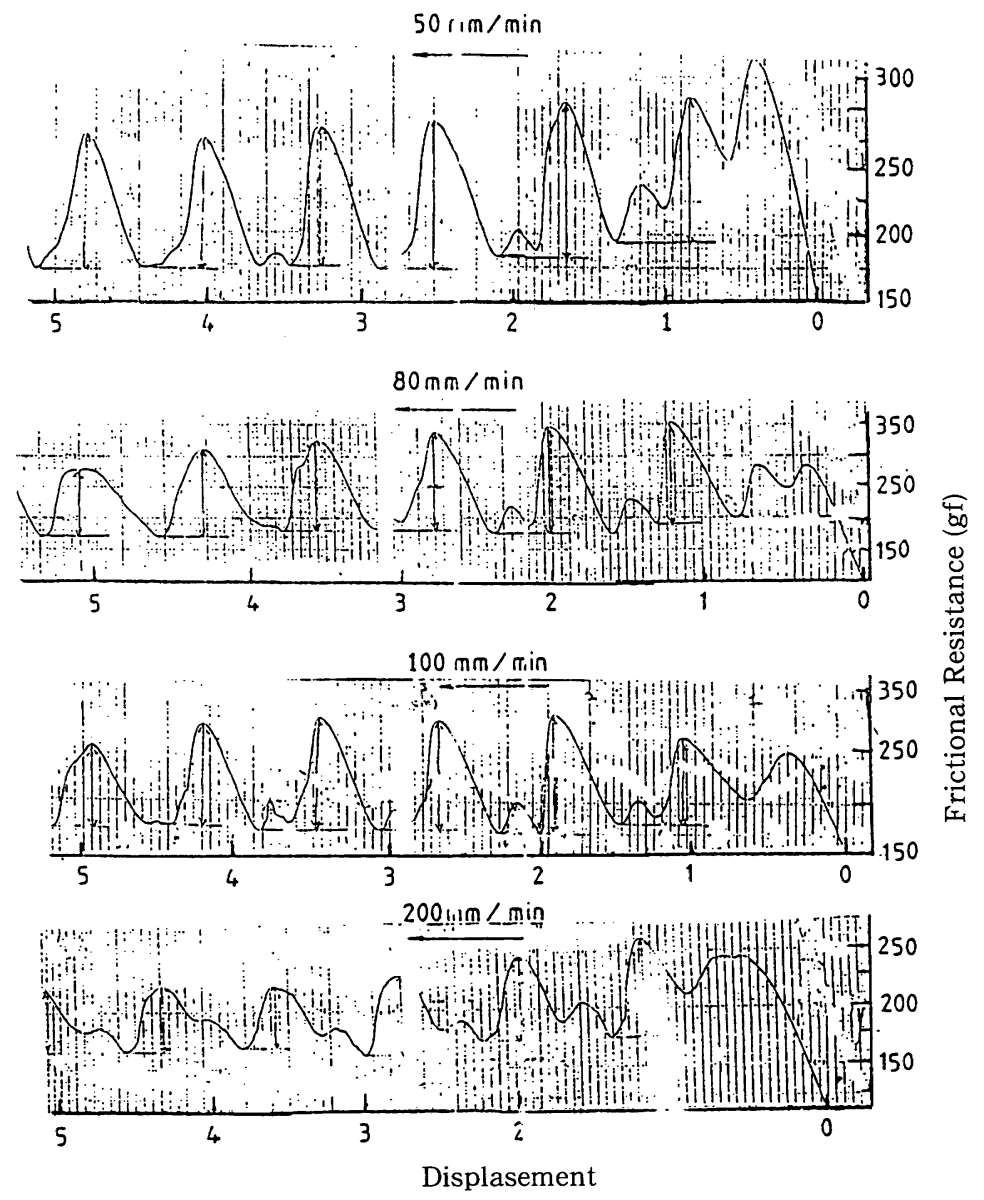

Fig. 7 Typical frictional traces of fabric $p_{1}$ at different velocities.

thus the amplitude of frictional resistance, FsFo, in equation 12 , will diminish as the velocity of sliding increase. That is, any increase in the velocity of sliding should decrease the time of contact and hence reduce amplitude of resistance.

An important characteristic of corduroys in general is the ridginess of fabric surface. An examination of friction traces such as that shown in Fig. 7 permits such features to be objectively characterized and related to fabric handle and texture ${ }^{1-5,14,15)}$. The effects of sled velocity on the stick-slip phenomenon can also be visually discerned. Fig. 7 shows a typical frictional resistance versus displacement curve for fabric $P_{1}$. This Figure depicts that there are clearly two different kinds of cords on the sur- face of fabric $P_{1}$. The amplitudes yielded by these cords diminish as the velocity of sliding increase. This may imply a poorer discrimination at higher speeds. From the results of other fabrics examined, it was generally observed that the greater the stick-slip peaks, and their amplitudes, the higher the effects of velocity.

\section{Conclusion}

1. The number of cords in weft fabrics is linearly correlated with the number of peaks of the stick-slip motion. However, the number of stick-slip peaks detected by using the friction assembly is slightly lower than the actual number of cords on fabric surface. These results are attributed to the bluntness of the friction probe. 
2. The amplitude of the stick-slip pulses, is linearly related to the cord height on pile fabrics.

3. The frictional amplitude diminishes while the number of peaks remain approximately constant as the velocity of sliding increases.

4. The kinetic frictional resistance decrease initially and then rise again as the velocity of sliding increase. The initial decrease was attributed to the viscoelastic properties of po lymeric materials while the increase in resistance was attributed to mechanical interlocking of surface structure.

\section{References}

1) J. O. Ajayi, Ph. D. Thesis ; University of Strathclyde, Glasgow, 1988.

2) J. O. Ajayi and H. M. Elder ; J. Test. and Eva., 22, 465, (1994).
3) J. O. Ajayi, Text. Res. J., 62, 87, 1992.

4) J. O. Ajayi and H. M. Elder, J. Test. and Eva., 23, 55, 1995.

5) J. O. Ajayi, Text. Res. J., 62, 52 (1992).

6) T. Nishimatsu and T. Sawaki ; J. Text. Mech. Soc. Japan, 35, T67, 1982.

7) T. Nishimatsu and T. Sawaki ; J. Text. Mech. Soc. Japan, 35, T100, (1982).

8) H. G. Howell, K. W. Mieszkis and D. Tabor ; "Friction in Textiles" Butterworths and Textile Institute, London, 1959.

9) H. L. Roder ; J. Text. Inst., 44, T247, (1953).

10) J. S. Olsen ; Text. Res. J., 31, (1969).

11) A. R. Kalyanaraman ; Indian J. Text. Res., 13, 1, (1988).

12) F. P. Bowden and D. Tabor, ; "Friction and Lubrication of Solids", Oxford Claredon Press, London, 1964.

13) ASTM D1984, American Society for Testing and Materials.

14) M. U. Darma, M. Sc. Thesis ; Ahmadu Bello University, Zaria, 1992.

15) J. O. Ajayi and H. M. Elder ; J. Text. Inst., 86, 600, (1995). 